\title{
Does living in urban or rural settings affect aspects of physical fitness in children? An allometric approach
}

\author{
P D Tsimeas, A L Tsiokanos, Y Koutedakis, N Tsigilis, S Kellis
}

Br J Sports Med 2005;39:671-674. doi: 10.1136/bjsm.2004.017384

See end of article for authors' affiliations ......................

Correspondence to: Dr Panagiotis D Tsimeas, Thessaly University, Department of Sports and Exercise Science, Trikala, Greece; ptsimeas@ pe.uth.gr

Accepted 6 February 2005
Objective: The aim of this study was to investigate physical fitness in relation to fatness in urban and rural Greek children by means of allometric scaling.

Methods: The sample consisted of 360 (189 urban and 171 rural; age $12.3 \pm 0.42$ years) boys and 247 (125 urban and 122 rural; age $12.3 \pm 0.43$ years) girls. The sample was highly representative (32-64\%) of all 12 year old children registered in the prefecture of Trikala, Greece. All volunteers were assessed for $\mathrm{BMI}$ and \% body fat, as well as sit and reach, basketball throw (BT), vertical jump (VJ), handgrip strength (HG), $40 \mathrm{~m}$ sprint, agility run, and $20 \mathrm{~m}$ shuttle run. To correct for possible associations between fatness and fitness, a single cause allometric scaling was employed using the natural logarithms (In) of fitness parameters that were significantly correlated with the ln body fat.

Results: Independent-samples $t$ tests revealed that $\mathrm{VJ}(p<0.05)$ was significantly higher in boys living in urban settings compared to their rural counterparts. Similarly, BT was found to be significantly better $(p<0.05)$ in urban girls, whereas HG was significantly higher $(p<0.05)$ in rural girls.

Conclusion: Considering that (a) only three out of the 14 possible cases (seven fitness parameters for boys and seven for girls) were significantly different between urban and rural children, and (b) these differences were not uniformly distributed in children living in either urban or rural environments, it is concluded that the place of residence has no clear impact on physical fitness as studied herein.
1 ncreased body fatness is a global epidemic. ${ }^{1}$ In adults, ample epidemiological evidence demonstrates a positive association between body fat levels and a greater health risk of all-cause mortality. ${ }^{2}$ Similarly, children with increased body fat are more likely to display aberrant CHD risk factor profiles, $^{3}$ demonstrate orthopaedic complications, and develop a distorted self image that appears to persist into adulthood. ${ }^{4}$

Body composition in general and body fatness in particular may also affect physical fitness components. For instance, a cross-sectional study has shown that obese Hungarian children have lower aerobic fitness ${ }^{5}$ than their non-obese counterparts. On a similar note, Greek children demonstrate increased prevalence of obesity ${ }^{6}$ and, compared to their counterparts from other countries, low aerobic fitness levels. ${ }^{7}$

Living in areas distinguished by population size can be associated with differences in, inter alia, eating habits, access to sports facilities, and opportunities for physical fitness activities. ${ }^{8}{ }^{9}$ However, it is not entirely clear whether such factors can affect aspects of body composition and, therefore, physical fitness.

While some data indicated that urban children have more body fat than their rural counterparts, ${ }^{10}$ other data are in strong disagreement. ${ }^{11}$ Contradictory reports have also been published in relation to physical fitness parameters in children living in urban and rural settings. ${ }^{12-15}$ In some cases, no differences have been identified in a range of fitness and motor skill measures between children from urban and rural areas. ${ }^{16}$

It has been suggested that the distribution of children's health related fitness across geographic boundaries needs to be studied in different climatic, economic, and cultural contexts. ${ }^{17}$ Furthermore, several studies have used an allometric approach to study fitness in children. ${ }^{18} 19$ This technique provides a truly dimensionless expression of data which can be used in subsequent comparisons between groups that differ in body characteristics, ${ }^{20}$ such as body fat.
To our knowledge, there is a dearth of such data on Greek children. Therefore, the aim of this study was to investigate physical fitness in relation to fatness in urban and rural Greek children by means of allometric scaling.

\section{METHODS}

This study is part of a larger investigation on aspects of fitness in European children. We present a cross-sectional analysis of the effects of geographical area of residence on a variety of physical fitness determinants corrected for body fat.

\section{Geographical area of residence (urban $v$ small towns or rural areas)}

Definitions of urban and rural areas are inconsistent. They are based on variables such as distance from trading centres and cut off population sizes of 100000,50000 , and 10000 inhabitants. ${ }^{21}$ The latter criterion was used in this study to describe an urban area (>10 000 inhabitants) and a rural area $(<10000$ inhabitants).

\section{Subjects}

The sample consisted of 360 (189 urban and 171 rural; age $12.3 \pm 0.42$ years) boys and 247 ( 125 urban and 122 rural; age $12.3 \pm 0.43$ years $)$ girls with no medical history of disease. Volunteers were recruited from four randomly selected schools in the town of Trikala, Greece (population $\sim 70000$ ) and from four randomly selected schools in the surrounding villages (population $<2000$ in each village). Urban volunteers represented approximately $40 \%$ and $32 \%$ of all 12 year old boys and girls, respectively, while their rural counterparts represented approximately $64 \%$ and 53\% of all 12 year old boys and girls in the prefecture of Trikala,

Abbreviations: $20 \mathrm{mSR}, 20 \mathrm{~m}$ shuttle run; $A R$, agility run; $B T$, basketball throw; HG, handgrip strength; ln, natural logarithms; SR, sit and reach; VJ, vertical jump 
respectively. The participation rates for first grade pupils from all eight schools were $96 \%$ and $90 \%$ for boys and girls, respectively. The Research Ethics Committee of the University of Thessaly approved the investigation and permission was granted by the Greek Ministry of Education. Written informed consent was obtained from all volunteers and their parents after full explanation of the procedures involved.

\section{Data collection}

Procedures took place during morning school visits from September to December 2001, 2002, and 2003. Demonstrations of each test were given to children prior to testing. All measurements were conducted by the same investigating team, following the same order of testing, and allowing 5-10 min rest intervals between tests. These measurements and tests will be presented in the order in which they were conducted.

\section{Anthropometry}

Standing height was measured to the nearest $0.5 \mathrm{~cm}$ using a Seca Stadiometer 208 (Seca, Hamburg, Germany), with the subject's shoes off and head in the Frankfort horizontal plane. Body mass was assessed to the nearest $0.5 \mathrm{~kg}$ (Seca Beam Balance 710). BMI was calculated as weight/height ${ }^{2}$. Percentage body fat was calculated from two skinfolds, that is, triceps and subscapular (average of two measurements) with a Harpenden calliper (British Indicators, St Albans, UK) using an established formula. ${ }^{22}$

\section{Physical fitness tests}

Physical fitness was assessed using seven field tests which have been previously validated for use in paediatric populations. ${ }^{23}$ For all but the last test, two trials were allowed and the best score was recorded for further analyses. These tests are described below.

\section{Sit and reach (SR)}

The sit and reach test was used to assess flexibility of the spine and posterior leg muscles. Each subject was asked to sit on the gymnasium floor, with knees straight and resting their bare feet vertically against a box $30 \mathrm{~cm}$ in height. To perform the test, the subject leaned forward with straight arms and knees and reached over the top surface of the box. The distance between toes and finger was measured. Positive values were recorded if the subject was able to reach further than his/her toes, negative values were recorded if the subject was unable to reach his/her toes, and a zero value was given when subjects just touched their toes.

\section{Basketball throw (BT)}

The test involved throwing a standard size and weight senior basketball in the horizontal direction as far as possible, from a sitting position. The participant was asked to sit on the gymnasium floor with straight legs, while buttocks, back, and head were resting against a wall. The participant uses a two-handed chest pass to push the ball.

\section{Handgrip (HG)}

Subjects had to squeeze a calibrated hand dynamometer as forcefully as possible with the preferred hand. The handle length was adjusted to account for variations in hand size.

\section{Vertical jump test (VJ)}

Following a short familiarisation period, volunteers performed the required jumps from a squatting position $\left(90^{\circ}\right.$ knee angle with hands on hips). A jump meter with a digital display (T.K.K. 5106 JUMP MD; Takei Scientific Instruments,
Tokyo, Japan) was used. The jump height was recorded in centimetres.

\section{$40 \mathrm{~m}$ sprint $(40 \mathrm{~m})$}

The volunteer started the test from a standing position with one foot on the starting line. The timer stood at the finish line, called ready, and signalled the start of the sprint. Timing was initiated by the first movement of the subject. Time was recorded to the nearest $0.1 \mathrm{~s}$.

\section{Agility $10 \times 5 \mathrm{~m}$ run $(A R)$}

Two lines $5 \mathrm{~m}$ apart were drawn on the gymnasium floor. On the command of "go", the pupil had to run forward as quickly as possible, pivot on the far line, and return to the starting line. This had to be repeated five times in total. The time required to complete the test was recorded to the nearest $0.1 \mathrm{~s}$.

\section{0 m shuttle run (20 mSR)}

Subjects performed the test individually and were instructed to run between two lines $20 \mathrm{~m}$ apart in synchrony with a sound signal emitted from an audiocassette. The frequency of signals increased by $0.5 \mathrm{~km} / \mathrm{h}$ each minute from a starting speed of $8.5 \mathrm{~km} / \mathrm{h}$. The test was terminated when subjects were unable to maintain the prescribed pace for three consecutive signals. The equivalent shuttle running speed was used as an endurance performance indicator. ${ }^{24}$

\section{Statistical analyses}

The Kolmogorov-Smirnov test of normality revealed that none of the studied variables required logarithmic transformation. Correlation coefficients were calculated between the natural logarithm (ln) of body fat and the seven ln physical fitness tests for boys and girls separately. Significantly correlated parameters were then used to calculate power function ratios by means of allometric scaling. ${ }^{25}$ The Kolmogorov-Smirnov test was again used to ensure that the calculated power function ratios were also normally distributed. The independent samples $t$ test was utilised to assess for differences between urban and rural settings. The significance level was set at $\mathrm{p}<0.05$.

\section{RESULTS}

Although body fat was found to be higher than that which is universally regarded as acceptable for boys and girls of this age, no statistical differences were found between our urban and rural children (tables 1 and 2). Independent-samples $t$ tests revealed that VJ $(\mathrm{p}<0.05)$ was significantly higher in boys living in urban settings compared to their rural counterparts. In girls, BT was found to be significantly better $(p<0.05)$ in the urban children, whereas HG was significantly higher $(\mathrm{p}<0.05)$ in the rural subjects (tables 1 and 2$)$. No further statistical differences were established.

Table 1 Fatness and fitness parameters in urban and rural Greek boys

\begin{tabular}{lcc}
\hline Parameters & Urban & \multicolumn{1}{l}{ Rural } \\
\hline BMl $\left(\mathrm{kg} / \mathrm{m}^{2}\right)$ & $21.0 \pm 3.4$ & $20.5 \pm 3.4$ \\
Body fat $(\%)$ & $21.0 \pm 7.8$ & $19.4 \pm 7.9$ \\
SR $(\mathrm{cm})$ & $14.3 \pm 6.1$ & $14.5 \pm 6.0$ \\
BT $(\mathrm{m})$ & $4.7 \pm 0.9$ & $4.6 \pm 0.8$ \\
VJ $(\mathrm{cm})$ & $48.6 \pm 7.7 \dagger$ & $46.9 \pm 7.5 \dagger$ \\
$\mathrm{HG}(\mathrm{kg})$ & $26.7 \pm 5.4 \dagger$ & $27.3 \pm 5.5 \dagger$ \\
$40 \mathrm{~m}(\mathrm{~s})$ & $5.2 \pm 0.5 \dagger$ & $5.2 \pm 0.4 \dagger$ \\
$\mathrm{AR}(\mathrm{s})$ & $17.0 \pm 1.5 \dagger$ & $17.0 \pm 1.0 \dagger$ \\
$20 \mathrm{mSR}(\mathrm{km} / \mathrm{h})$ & $15.1 \pm 1.3 \dagger$ & $15.1 \pm 1.0 \dagger$ \\
\hline \multirow{2}{*}{$\mathrm{p}<0.05, t$ test; †power function ratio. } \\
Data are means \pm SD.
\end{tabular}


Table 2 Fatness and fitness parameters in urban and rural Greek girls

\begin{tabular}{lcr}
\hline Parameters & Urban & Rural \\
\hline BMI $\left(\mathrm{kg} / \mathrm{m}^{2}\right)$ & $20.9 \pm 3.3$ & $20.5 \pm 3.3$ \\
Body fat $(\%)$ & $25.6 \pm 6.7$ & $24.8 \pm 6.8$ \\
SR $(\mathrm{cm})$ & $19.3 \pm 6.5$ & $18.6 \pm 6.4$ \\
BT $(\mathrm{m})$ & $4.0 \pm 0.7$ & $3.8 \pm 0.6^{*}$ \\
VJ $(\mathrm{cm})$ & $59.0 \pm 7.7 \dagger$ & $58.0 \pm 9.0 \dagger$ \\
$\mathrm{HG}(\mathrm{kg})$ & $20.0 \pm 4.0$ & $21.1 \pm 4.2^{*}$ \\
$40 \mathrm{~m}(\mathrm{~s})$ & $4.9 \pm 0.4 \dagger$ & $5.0 \pm 0.4 \dagger$ \\
AR $(\mathrm{s})$ & $16.9 \pm 1.3 \dagger$ & $16.7 \pm 1.0 \dagger$ \\
$20 \mathrm{mSR}(\mathrm{km} / \mathrm{h})$ & $13.9 \pm 0.9 \dagger$ & $13.9 \pm 0.8 \dagger$ \\
\hline
\end{tabular}

${ }^{*} \mathrm{p}<0.05, t$ test; tpower function ratio.

Data are means \pm SD.

Table 3 shows the $\mathrm{b}$ exponents derived from the allometric equation fitness parameter $=\alpha \times$ body fat ${ }^{b}$, where $\alpha$ is constant. It is noteworthy that these equations were employed to adjust for body fatness, mainly in relation to running and jumping test parameters.

\section{DISCUSSION}

In line with previously published reports on Greek children, ${ }^{6}{ }^{26}$ the present data have demonstrated that Greek children from both urban and rural areas have higher body fat levels than considered healthy for boys ( $\leqslant 15 \%$ body fat) and girls ( $\leqslant 20 \%$ body fat) of this age group. ${ }^{27}$ Given that body fat negatively affects various aspects of physical fitness, ${ }^{728}$ adjustment of the studied fitness parameters for body fat would better serve the aims of this study.

The principal aim of the current study was to examine potential differences in aspects of physical fitness in Greek children living in either urban or rural settings. To correct for possible associations between fatness and fitness, a single cause allometric scaling was employed using the natural logarithms of fitness parameters that were significantly correlated with the ln body fat. The main findings were that only three out of the 14 possible cases (seven fitness parameters for boys and seven for girls) were significant different between urban and rural children and that these differences were not uniformly distributed in children living in either urban or rural environments. It is, therefore, tempting to suggest that, for Greek children, the place of residence has no clear impact on physical fitness as studied herein.

The advantages of allometric scaling over other procedures for examining size-independent performance scores have been detailed elsewhere. ${ }^{29}$ To our knowledge, this is the first study which examined selected physical fitness components in urban and rural children using the above method. Nevertheless, the present data do not agree with published reports advocating that the place of residence indeed has an impact on children's fitness. Specifically, it has been found

Table 3 Derived exponents for $b$ in the formula: fitness $=\mathrm{a} \times$ body fat ${ }^{\mathrm{b}}$ for boys and girls

\begin{tabular}{lrr}
\hline Parameters & \multicolumn{1}{c}{$\begin{array}{c}\text { Boys, } \\
\mathbf{b}_{\mathbf{b}}( \pm 95 \% \mathrm{Cl})\end{array}$} & \multicolumn{1}{c}{$\begin{array}{c}\text { Girls, } \\
\mathbf{b}_{\mathbf{g}}( \pm 95 \% \mathrm{Cl})\end{array}$} \\
\hline VJ & $-0.14 \pm 0.04$ & $-0.22 \pm 0.06$ \\
$\mathrm{HG}$ & $0.06 \pm 0.05$ & - \\
$40 \mathrm{~m}$ & $0.11 \pm 0.02$ & $0.13 \pm 0.04$ \\
AR & $0.07 \pm 0.02$ & $0.09 \pm 0.03$ \\
$20 \mathrm{mSR}$ & $-0.12 \pm 0.02$ & $-0.11 \pm 0.03$ \\
\hline
\end{tabular}

$a$, constant; $b_{b}$, common $b$ exponent for urban and rural areas for boys; $b_{g}$, common $b$ exponent for urban and rural areas for girls.
What is already known on this topic

Contradictory reports exist in relation to children living in urban and rural settings and selected physical fitness parameters. The latter can be affected by body fatness. Allometric scaling provides a truly dimensionless expression of data which can be used in subsequent comparisons between groups that differ in body characteristics, such as body fat.

\section{What this study adds}

This study examines physical fitness in relation to fatness, between urban and rural Greek children by means of allometric scaling. This is the first study that utilises allometric procedures to compare fitness parameters between paediatric samples living in areas distinguished by population size. The place of residence (urban $v$ rural areas) has no clear impact on physical fitness in 12 year old Greek school children.

that US ${ }^{11}$ urban children have superior fitness levels compare to those living in rural areas, whereas a report from Poland proposed that rural children were fitter than their urban counterparts. $^{30}$ Methodological differences, such as the criterion used to define rural versus urban areas, variability in tests used to assess fitness levels, and statistical analyses may account for the discrepancies in the literature.

One potentially important factor behind the lack of statistical differences in physical fitness in boys and girls living in urban and rural environments may be the national Greek physical education (PE) programmes. Irrespective of schools' size or location, state secondary school PE programmes are common and compulsory throughout Greece. However, it has been recently found that these programmes are insufficient to bring about beneficial adaptations in selected health related fitness parameters, such as maximal oxygen intake. ${ }^{31}$ These findings are also in line with existing data from other countries questioning the validity of school PE classes ${ }^{32}$ and partly contradict the assertion that school PE lessons should fulfil most of the fitness needs of children. ${ }^{33}$ The emerging trend towards urbanisation of Greek rural life ${ }^{34}$ may be an additional explanation for the present findings.

The lack of statistical differences between children living in urban and rural environments may be supported by the well established genetic basis of certain fitness components. ${ }^{35}$ It has been suggested, for instance, that aerobic fitness in children serves just as a proxy indicator of physical activity participation. ${ }^{36}$ However, low aerobic fitness reduces muscular fat oxidation capacity, which may decrease tolerance of dietary fat and increase adiposity. ${ }^{37}$ On the other hand, adequate body fat in young females is necessary for menarche to occur and this can be partly achieved through reduced physical activity levels, suggesting the existence of an energy conserving mechanism in favour of fat accumulation. ${ }^{38}$

The results of this study confirm the importance of body fatness as a negative influence on performance in running and jumping tests. It is noteworthy that all running and jumping parameters tested were negatively associated with body fat. This finding is in accordance with previous published reports whereby body fat negatively affects jumping and running performance in both children ${ }^{39}$ and adults. ${ }^{40}$ 
In conclusion, and within this study's limitations, including data collection from a single geographical region, it is suggested that the place of residence has no clear impact on physical fitness in 12 year old Greek school children. Further research is required involving allometric scaling to study aspects of health and fitness in paediatric populations from different countries.

\section{ACKNOWLEDGEMENTS}

We thank the education authorities, school principals, teachers, children, and their parents for their enthusiastic support of the project.

\section{Authors' affiliations}

P D Tsimeas, A L Tsiokanos, Y Koutedakis, N Tsigilis, Department of Sports and Exercise Science, Thessaly University, Trikala, Greece S Kellis, Department of Sports and Exercise Science, Aristotle University, Thessaloniki, Greece

We thank the Greek State Scholarships Foundation (IKY) which supported this work

Competing interests: none declared

\section{REFERENCES}

1 World Health Organization. Obesity: preventing and managing the global epidemic, WHO Technical Report Series 894. Geneva: WHO, 2000.

2 Bender R, Trautner C, Spraul M, et al. Assessment of excess mortality in obesity. Am J Epidemiol 1998;147:42-8.

3 Ball G, Marshall J, McCargar L. Fatness and fitness in obese children at low and high health risk. Pediatr Exerc Sci 2003;15:392-405.

4 Wabitsch M. Overweight and obesity in European children: definition and diagnostic procedures, risk factors and consequences for later health outcome. Eur J Pediatr 2000;159(suppl 1):S8-13.

5 Torok K, Szelenyi Z, Porszasz J, et al. Low physical performance in obese adolescent boys with metabolic syndrome. Int J Obes Relat Metab Disord 2001;25:966-70.

6 Mamalakis G, Kafatos A. Prevalence of obesity in Greece. Int J Obes Relat Metab Disord 1996;20:488-92.

7 Bouziotas C, Koutedakis Y, Shiner R, et al. The prevalence of selected modifiable coronary heart disease risk factors in 12-year-old Greek boys and girls. Pediatr Exerc Sci 2001;13:173-84.

8 Kabagambe EK, Baylin A, Siles X, et al. Comparison of dietary intakes of micro- and macronutrients in rural, suburban and urban populations in Costa Rica. Public Health Nutr 2002;5:835-42.

9 Parks SE, Housemann RA, Brownson RC. Differential correlates of physical activity in urban and rural adults of various socioeconomic backgrounds in the United States. J Epidemiol Community Health 2003;57:29-35.

10 Mamalakis G, Kafatos A, Manios Y, et al. Obesity indices in a cohort of primary school children in Crete: a six year prospective study. Int J Obes Relat Metab Disord 2000;24:765-71.

11 McMurray RG, Harrell JS, Bangdiwala SI, et al. Cardiovascular disease risk factors and obesity of rural and urban elementary school children. J Rural Health 1999;15:365-74.

12 Ewing BG, Watkins J, Farrally M. Physical fitness and anthropometry of Scottish schoolboys. Part 3. Scott J Phys Educ 1982;10:14-20.

13 Wilczewski A, Sklad M, Krawczyk B, et al. Physical development and fitness of children from urban and rural areas as determined by EUROFIT test battery. Biol Sport 1996;13:113-26.

14 McMurray RG, Harrell JS, Bangdiwala SI, et al. Biologic and environmental factors influencing the aerobic power of children. Med Exerc Nutr Health 1995;4:243-50.
15 Sunnegardh J, Bratteby LE, Sjodin S. Physical activity and sports involvement in 8- and 13-year-old children in Sweden. Acta Paediatr Scand 1985;74:904-12

16 Krombholz $\mathbf{H}$. Physical performance in relation to age, sex, social class and sports activities in kindergarten and elementary school. Percept Mot Skills 1997;84: 1168-70.

17 Dollman J, Norton K, Tucker G. Anthropometry, fitness and physical activity of urban and rural south Australian children. Pediatr Exerc Sci 2002; 14:297-312

18 Armstrong N, Welsman JR. Peak oxygen uptake in relation to growth and maturation in 11- to 17-year-old humans. Eur J Appl Physiol 2001;85:546-51

19 Rowland T, Miller K, Vanderburgh P, et al. Cardiovascular fitness in premenarcheal girls and young women. Int J Sports Med 2000;21:117-21.

20 Schmidt-Nielsen K. Scaling: why is animal size so important? Cambridge: Cambridge University Press, 1984.

21 United Nations. World urbanization prospects: the 2001 revision. New York: United Nations, 2002

22 Boileau RA, Lohman TG, Slaughter MH. Exercise and body composition in children and youth. Scand J Med Sci Sports 1985;1:17-27.

23 Docherty D, ed. Measurement in pediatric exercise science. Champaign, IL: Human Kinetics, 1996.

24 Scott BK, Houmard JA. Peak running velocity is highly related to distance running performance. Int J Sports Med 1994;15:504-7.

25 Winter EM. Scaling: partitioning out differences in size. Pediatr Exerc Sci 1992;4:296-301.

26 Bouziotas C, Koutedakis Y, Nevill A, et al. Greek adolescents, fitness, fatness, fat intake, activity, and coronary heart disease risk. Arch Dis Child 2004:89:41-4.

27 Bell RD, Macek M, Rutenfranz J, et al. Health indicators and risk factors of cardiovascular diseases during childhood and adolescence. In: Rutenfranz J, Mocellin R, Klimt F, eds. International series on sport sciences. Vol 17. Children and exercise XII. Champaign, IL: Human Kinetics, 1986:19-27.

28 Dollman J, Norton K, Tucker G. Anthropometry, fitness and physical activity of urban and rural south Australian children. Pediatr Exerc Sci 2002; 14:297-312.

29 Nevill AM, Ramsbottom R, Williams C. Scaling physiological measurements for individuals of different body size. Eur J Appl Physiol Occup Physiol 1992;65:110-7.

30 Wilczewski A, Sklad M, Krawczyk B, et al. Physical development and fitness of children from urban and rural areas as determined by EUROFIT test battery. Biol Sport Warsaw 1996;13:113-26.

31 Koutedakis $Y$, Bouziotas $C$. National physical education curriculum: motor and cardiovascular health related fitness in Greek adolescents. Br J Sports Med 2003;37:311-4.

32 Shephard RJ. Physical activity, aerobic fitness, and health. In: Aerobic fitness and health. Champaign, IL: Human Kinetics, 1994:1-29.

33 Sallis JF, McKenzie TL. Physical education's role in public health. Res Q Exerc Sport 1991;62:124-37.

34 Anastassea-Vlachou K, Fryssira-Kanioura H, Papathanasiou-Klontza D, et al. The effects of television viewing in Greece, and the role of the paediatrician: a familiar triangle revisited. Eur J Pediatr 1996;155:1057-60.

35 Klissouras V, Pirnay F, Petit JM. Adaptation to maximal effort: genetics and age. J Appl Physiol 1973;35:288-93

36 Johnson M, Figueroa-Colon R, Herd S, et al. Aerobic fitness, not energy expenditure, influences subsequent increase in adiposity in black and white children. Pediatrics 2000;106:E50.

37 Ekelund U, Aman J, Yngve A, et al. Physical activity but not energy expenditure is reduced in obese adolescents: a case control study. Am J Clin Nutr 2002;76:935-41.

38 Goran MI, Reynolds KD, Lindquist CH. Role of physical activity in the prevention of obesity in children. Int J Obes Relat Metab Disord 1999;23(suppl 3):S18-33

39 Ara I, Vicente-Rodriguez G, Jimenez-Ramirez J, et al. Regular participation in sports is associated with enhanced physical fitness and lower fat mass in prepubertal boys. Int J Obes Relat Metab Disord 2004;28:1585-93.

40 Thomas TR, Zebas CJ, Bahrke MS, et al. Physiological and psychological correlates of success in track and field athletes. Br J Sports Med 1983;17:102-9. 